\title{
Potential Benefit of Repeated Dry Powder Inhaler's Inhalation Technique Counseling on Asthmatic Patients
}

\author{
Marwa O. Elgendy $\cdot$ Mohamed E. Abdelrahim $\cdot$ Randa Salah Eldin
}

To view enhanced content go to www.pulmonarytherapy-open.com

Received: August 18, 2015 / Published online: October 5, 2015

(C) The Author(s) 2015. This article is published with open access at Springerlink.com

\section{ABSTRACT}

The aim of the work presented here was to determine the role of dry powder inhaler (DPI) counselling on inhalation technique and lung function test scores of the asthmatic patients. To decrease variability, asthmatic patients using an Aerolizer were enrolled in the study, as this was the most commonly prescribed DPI in outpatient clinics of Beni Suef University hospital. Each patient was subjected to three visits separated by 1 month each. In each visit, patient inhalation technique from the DPI was checked, and the number of mistakes was identified and corrected. Also, patients' peak expiratory flow (PEF) and forced expiratory volume in one second $\left(\mathrm{FEV}_{1}\right)$ presented as a percentage of the forced vital capacity (FVC)

M. O. Elgendy

Hospital Pharmacy Department, Teaching Hospital of Faculty of Medicine, Beni Suef University, Beni Suef, Egypt

M. E. Abdelrahim ( $₫)$

Clinical Pharmacy Department, Faculty of Pharmacy, Beni Suef University, Beni Suef, Egypt e-mail: Mohamed.abdelrahim@pharm.bsu.edu.eg

R. S. Eldin

Respiratory Department, Faculty of Medicine, Beni Suef University, Beni Suef, Egypt were checked. As the number of visits increased, the mean number of observed mistakes was significantly decreased $(p<0.001)$. The most common repeated mistakes were "To inhale fast" and "To maintain a fast inhalation rate until the lungs are full". In all age groups, there was a significant increase $(p<0.001)$ in the pulmonary function test after the period of counselling. To improve and maintain the recommended inhalation technique of DPI and possibly improve patients' lung function test scores, counselling on proper DPI technique should be repeated at every possible opportunity.

Keywords: Aerolizer; Asthma; Counselling; Dry powder inhaler; $\mathrm{FEV}_{1}$; Number of mistakes; PEF

\section{INTRODUCTION}

Inhalers are the most common type of medication devices used to treat obstructive lung diseases. However, they are often not properly used, leading to uncontrolled disease and increased costs [1]. This remains a common problem in obstructive lung diseases [2-4]. A 
call for action to the medical community recently published in the European Respiratory Journal explained how training in proper technique might be of practical importance [5]. The worldwide costs associated with the management of asthma and chronic obstructive pulmonary disease (COPD) in adults and children are very large, from both the healthcare payer and the societal points of view [6-10]. In a more than 10-year-old review of 21 studies looking at misuse of inhalers, poor technique was estimated to be prevalent in 14-90 \% (with an average of $50 \%$ ) of cases [11]. This level of misuse is still presented in recent studies [4, 12-17]. However, the same studies showed that a substantial increase in correct use occurred after training [4, 12-17]. Further improvement in correct use as well as lung function occurred with repeated counseling [4].

Poor inhalation technique may force the prescriber to step up treatment to control asthma. Hence, there is tremendous potential for improved inhalation technique to improve asthma control and reduce prescription costs.

For this reason, the aim of the present work was to study the effect of repeated counselling on inhalation technique for DPIs, as one of the most important devices in the treatment of obstructive lung diseases, for the asthmatic patients and its possible effect on the lung function test scores.

\section{METHODS}

Because each device has its own method of administration, we tried to decrease the number of variables by choosing one type of DPI that was most commonly prescribed to patients in Beni Suef University hospital outpatient clinics. By asking chest healthcare providers in outpatient clinics, it was found that Aerolizer
[Foradil (formoterol) and Miflonide (budesonide); Novartis, Egypt] was the most commonly prescribed DPI there. In this study, a number of asthmatic subjects using an Aerolizer DPI were collected from Beni Suef University hospital outpatient clinics throughout a 2-year period (from May 2013 to May 2015). To overcome the need for inclusion of a control group in the study, we chose patients that had been using, and were still using, an Aerolizer for at least 3 months prior to taking part in the study. Hence, patient results at the start of the study can be used as a baseline. An ethical approval was obtained from the University of Beni Suef for the study. All procedures followed were in accordance with the ethical standards of the responsible committee on human experimentation (institutional and national) and with the Helsinki Declaration of 1964, as revised in 2013. Informed consent was obtained from all patients for being included in the study.

Each patient was subjected to three visits separated by 1 month each. In each visit all the subjects were asked to show the investigator how they use their DPI. Investigator then detected and corrected the mistakes with the correct steps listed below. DPI inhalation technique was divided into steps as it was previously shown that the division could make the counselling more effective and enable investigator to detect the weaker steps [18-20].

\section{The Correct Method of Using DPI}

Step 1. Remove the protective cap from mouthpiece of the DPI.

Step 2. Prepare the DPI dose as instructed in the patient pamphlet.

Step 3. Breathe out as far as comfortable.

Step 4. Place the DPI mouthpiece between the teeth and seal with lips. 
Step 5. Ensure your tongue does not obstruct the mouthpiece.

Step 6. Inhale as fast and deep as possible.

Step 7. Maintain a fast inhalation rate until the lungs are full.

Step 8. Remove the DPI from the mouth and hold breath for 5-10 s.

Step 9. If more than one dose each time, wait about $30 \mathrm{~s}$ before the next dose.

Step 10. Rinse mouth, and if possible brush teeth after dosing.

Step 11. Replace cap on the DPI.

Each subject in each visit was asked to perform a pulmonary function test (PFT) using a handheld spirometer (One-Flow FVC Kit, Clement Clarke, UK) for measuring lung function. The outcome data were peak expiratory flow (PEF) in $\mathrm{L} / \mathrm{min}$ and forced expiratory volume in $1 \mathrm{~s}\left(\mathrm{FEV}_{1}\right)$ as percentage of the forced vital capacity (FVC).

Included subjects in the study were asthmatic subjects with an Aerolizer as prescribed inhaler to control their asthma and able to perform pulmonary function test correct. The patients started using the Aerolizer at least 3 months prior inclusion in the study. Thus, their first visit can be used as their own control.

\section{Statistical Analysis}

The analysis was made by Friedman test followed by Wilcoxon test for the comparison between the main variables and within-group comparison of $\mathrm{PEF}$ and $\mathrm{FEV}_{1} / \mathrm{FVC}$ percentage, and for mean number of mistakes of each visit.

Cochran test followed by McNemar test was used for the comparison between the results of total number of mistakes at each step of each visit.

The effect of age categories on DPI results (PEF and $\mathrm{FEV}_{1} / \mathrm{FVC}$ percentage and for mean number of mistakes of each visit) was analysed using two-way analysis of variance (ANOVA) test at $p<0.05$ followed by post hoc using Tukey system.

\section{RESULTS}

A number of 310 (164 female) asthmatic patients, with mean (SD, range) age 48.7 (13.1, 20-78) years old completed the study. Their results were studied as one whole group of patients and divided into three groups according to their age.

GP1 (<40 years old) was 89 (52 female) patients; GP2 (40-60 years old) was 160 (83 female) patients and GP3 (>60 years old) was 61 (29 female) patients.

There was no significant difference in all the tested parameters between male and female in all age groups. The mean (SD) of PEF, $\mathrm{FEV}_{1} /$ $\mathrm{FVC} \%$, and the number of mistakes are presented Table 1 and Fig. 1. PEF in GP3 was significantly lower than that of GP2 $(p=0.05)$. $\mathrm{FEV}_{1} / \mathrm{FVC} \%$ in GP3 was significantly lower than those of GP2 and GP1 $(p=0.001)$. There was no significant difference in number of mistakes between the three age groups in the three visits. The number of mistakes of each step in the three visits is presented in Table 2 and Fig. 2. Some steps showed no mistakes at all, and some showed mistakes that improved with counselling. Within each of those steps, there was a significant $(p<0.001)$ decrease in the number of mistake in the 2 nd visit than the 1st visit, followed by a significant $(p<0.001)$ decrease in the number of mistake in the 3rd visit. The only insignificant difference between two visits was between 2 nd and 1st visits in step 9 "If more than one dose each time, wait about 30 s before the next dose" and between 2nd and 3 st visits in steps 4 "Place the DPI mouthpiece between the teeth and seal with lips" and 8 
Table 1 Mean (SD) PEF, $\mathrm{FEV}_{1} / \mathrm{FVC} \%$, and number of mistakes in each visit

\begin{tabular}{llccc}
\hline & 1st visit & 2nd visit & 3rd visit & Overall $\boldsymbol{p}$ value \\
\hline PEF GP1 $(\mathrm{L} / \mathrm{min})^{*, \#}$ & $74.8(27.7)$ & $82(25.0)$ & $76.7(24.0)$ & $<0.05$ \\
PEF GP2 $(\mathrm{L} / \mathrm{min})^{\times}$ & $79.5(31.0)$ & $78.8(23.2)$ & $88.2(32.0)$ & $<0.001$ \\
PEF GP3 $(\mathrm{L} / \mathrm{min})^{*, \#}$ & $69.5(28.9)$ & $76.6(25.8)$ & $79.8(36.2)$ & $<0.05$ \\
PEF overall $(\mathrm{L} / \mathrm{min})$ & $76.2(29.8)$ & $79.3(24.2)$ & $83.3(31.2)$ & $<0.001$ \\
FEV $_{1} /$ FVC GP1 $(\%)^{*}$ & $77.5(15.2)$ & $81.0(13.4)$ & $85.9(13.5)$ & $<0.001$ \\
FEV $_{1} /$ FVC GP2 $(\%)^{*}$ & $76.4(16.1)$ & $78.5(13.9)$ & $86.0(12.7)$ & $<0.001$ \\
FEV $_{1} /$ FVC GP3 $(\%)^{*}$ & $70.5(18.0)$ & $74.7(14.9)$ & $81.3(16.2)$ & $<0.001$ \\
FEV $_{1} /$ FVC overall $(\%)$ & $75.5(16.4)$ & $78.5(14)$ & $85.0(13.8)$ & $<0.001$ \\
Number of mistakes GP1 $^{* *}$ & $4.0(1.2)$ & $2.9(1.1)$ & $1.9(1.1)$ & $<0.001$ \\
Number of mistakes GP2 $^{* *}$ & $3.9(1.0)$ & $3.0(1.0)$ & $1.6(1.1)$ & $<0.001$ \\
Number of mistakes GP3 ${ }^{* *}$ & $3.8(1.2)$ & $2.8(1.0)$ & $2.1(1.0)$ & $<0.001$ \\
Number of mistakes overall & $3.9(1.1)$ & $2.9(1.0)$ & $2.0(1.1)$ & $<0.001$ \\
\hline
\end{tabular}

$N S$ no significant difference

${ }^{\times}$No significant difference between 1 st and 2 nd visits

\# No significant difference between 2nd and 3rd visits

${ }^{*} p$ value between 1 st and 2 nd visits $<0.05,{ }^{* *} p$ value between 1 st and 2 nd visits $<0.001$

"Remove the DPI from the mouth and hold breath for 5-10s" with a high number of mistakes in the 2 nd visit. Percentage of correct steps of the three age categories in each visit is presented in Fig. 3. All the steps had comparable results in the three age categories.

\section{DISCUSSION}

It was previously shown that increasing patient knowledge about self-management by counselling can improve their adherence to the medications [21-24].

The present study permitted us to analyze the difficulties that these patients might have when using their DPI. Similar to previous studies, the results showed that most of the patients using a DPI did not perform correct inhalation technique in the 1 st visit, but they significantly improved in the 2nd $(p<0.001)$
$[17,25-27]$ and improved further in the 3rd visits $(p<0.001)$ [4]. Hence, repetition of the instructions can be significantly correlated with correct inhalation technique $(p<0.001)[4,28]$. The high number of errors observed at the 1st visit may lead to insufficient drug delivery, adversely influence drug efficacy, and may contribute to inadequate control of asthma [25]. That was observed in the low PEF and $\mathrm{FEV}_{1} / \mathrm{FVC} \%$ in the 1 st visit.

The steps with the highest number of mistakes were steps 6 and 7. Patients did not know that they had to inhale as fast and deep as possible from the DPI [13]. Also, it was very difficult to teach the patients to maintain a fast inhalation rate until the lungs were full. In the 2nd visit, patients improved slowly in the overall results of steps 6 and 7 compared to other steps. However, they showed much better improvement in the 3rd visit. With DPIs, the 

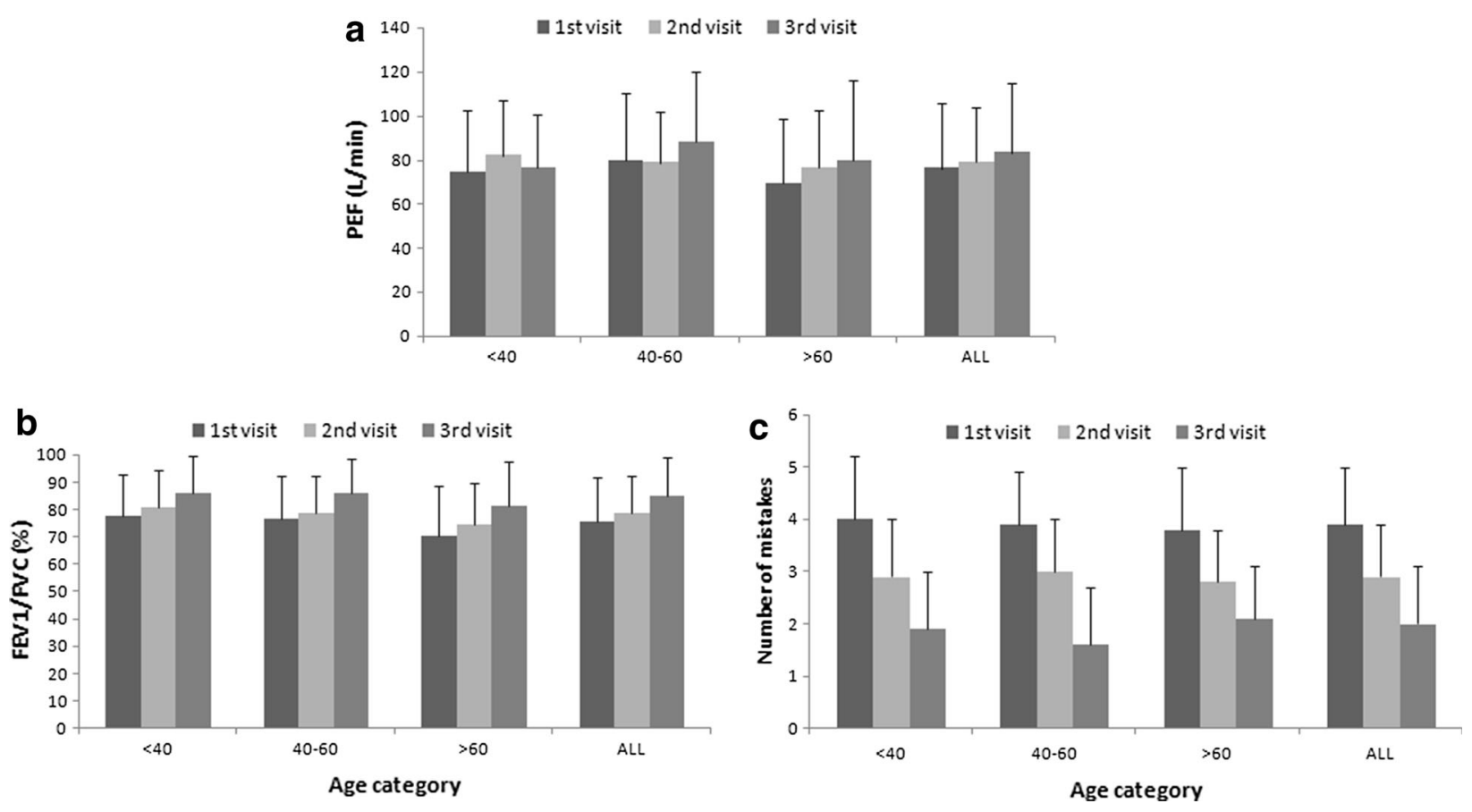

Fig. 1 a Mean (SD) PEF in each age group and the whole results together. b Mean (SD) FEV 1 /FVC\% in each age group and the whole results together. $\mathbf{c}$ Mean (SD) number of mistakes in each age group and the whole results together

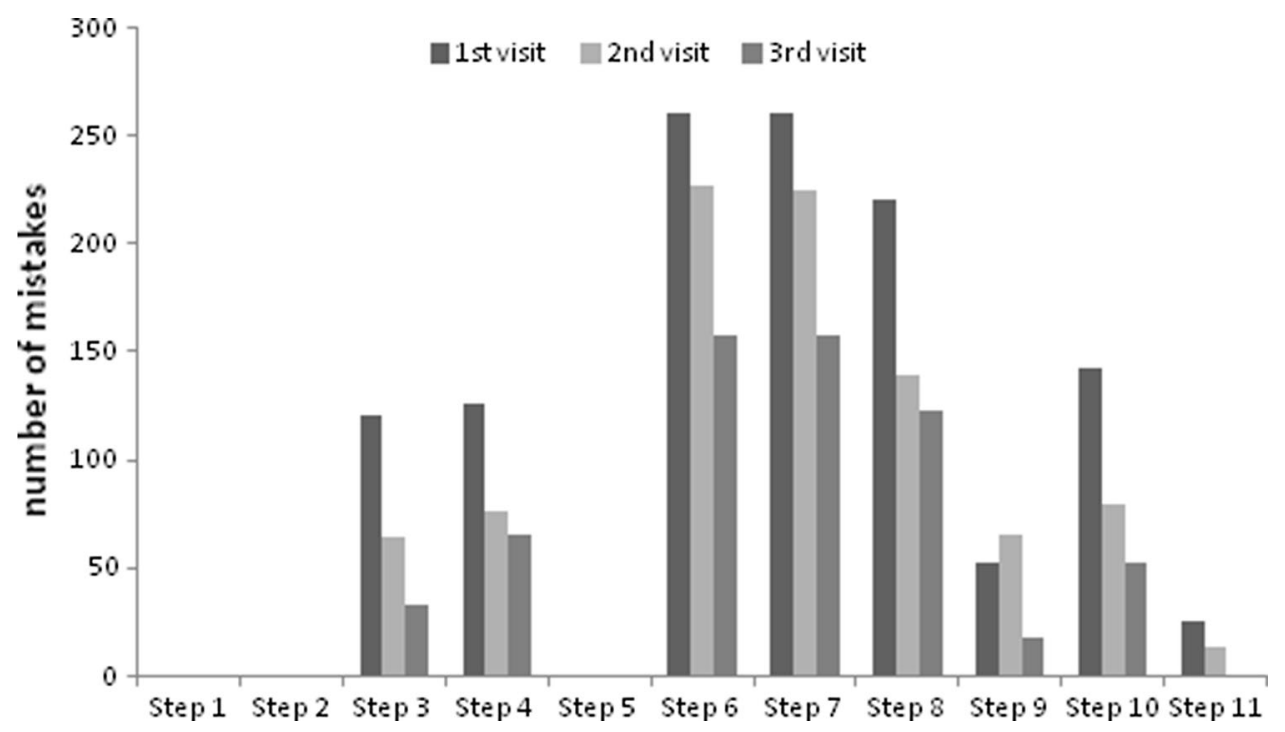

Fig. 2 Number of mistakes of each visit in each step

fine particle fraction and, consequently, lung deposition are dependent on inspiratory flow rate achieved by the patient [29-31]. That is affected mainly by steps 6 and 7. Thus, before prescribing a DPI, the patient should be checked for the ability to inhale deeply and forcibly for good lung drug deposition [25, 32]. The 3rd visit improvement in steps 6 and 7 support the recommendation that inhalers need reinforced counselling at every opportunity [4] as patients may forget or be uncertain of how to inhale fast and how to maintain a fast inhalation flow. 


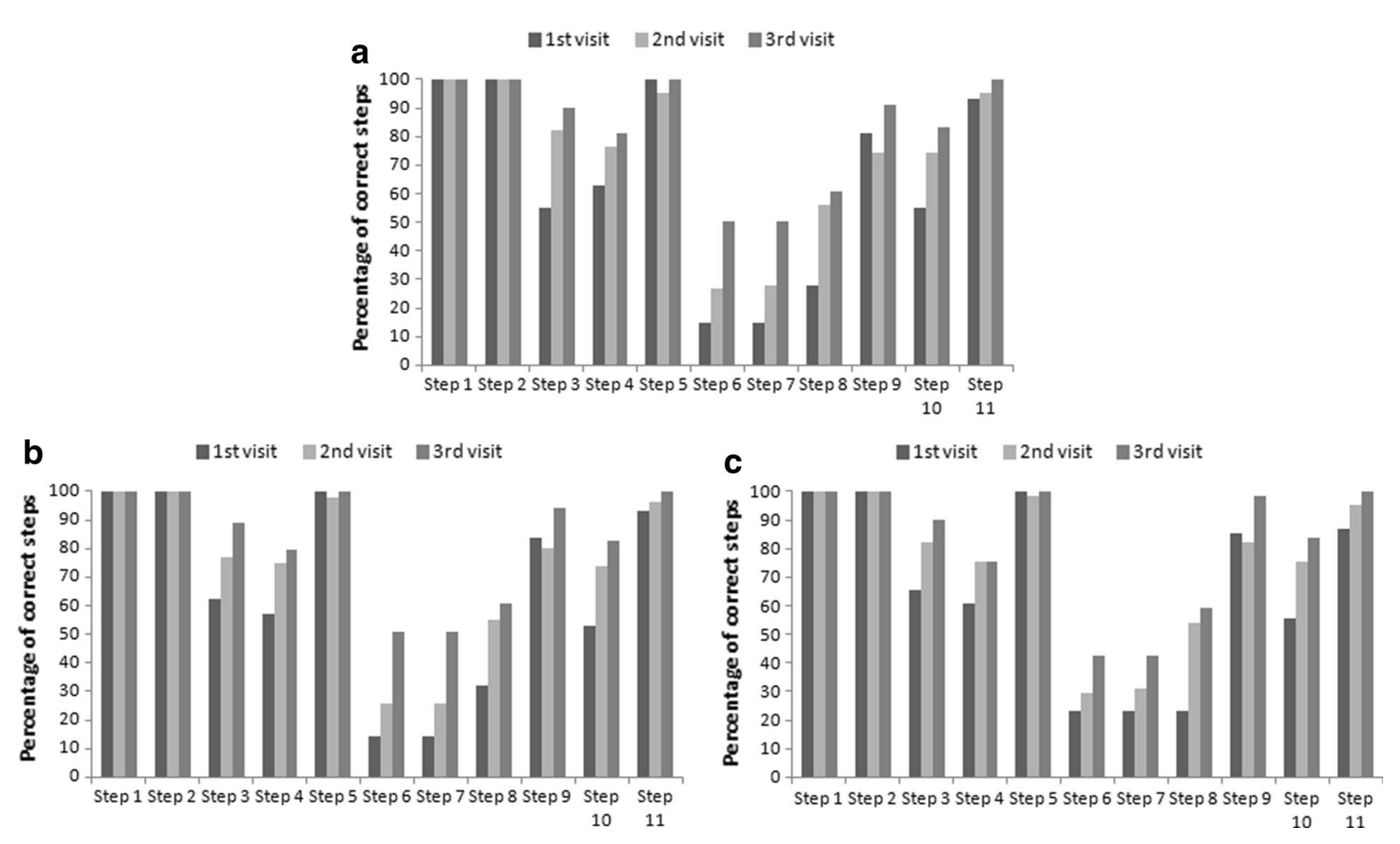

Fig. 3 Percentage of correct steps of the four age categories in each visit $\mathbf{a}<40$ years old, $\mathbf{b} 40-60$ years old, and $\mathbf{c}>60$ years old 40 years old, $\mathbf{b}>40-60$ years old and $\mathbf{c}>60$ years old

Some training devices can be used such as the In-Check Dial to help patients obtain the most desirable inhalation rate when using a DPI [33, 34]. The patient information leaflet provided with this training aid encourages patients to practice using the device in the same way that they would use their DPI [35].

The numbers of correct steps were improved by counselling in all age groups by going further in visits. Step 8 "Remove the DPI from the mouth and hold breath for 5-10 s", showed also slow improvement, but not as slow as steps 6 and 7 . Therefore, when counselling patients, more time should be given to those three steps to make sure they understand how to do them properly. Those three steps were believed to be related to patient technique and not related to the type of DPI [13]. Therefore, reinforcement of their correct technique at every opportunity can improve the inhalation technique of any DPI.
Steps 3 "Breathe out as far as comfortable", 4 "Place the DPI mouthpiece between the teeth and seal with lips", 9 "If more than one dose each time, wait about $30 \mathrm{~s}$ before the next dose", 10 "Rinse mouth, and if possible brush teeth after dosing", and 11 "Replace cap on the DPI" had a much higher significant improvement in the 2nd visit $(p<0.001)$ compared to steps 6,7 , and 8 . Hence, they could be much easier to be remembered when taught well.

An insignificant number of patients during step 3, "Breathe out as far as comfortable", exhaled through the mouthpiece of the DPI. That can cause a humidity increase within the DPI, which might cause variance in delivered dose [36, 37].

Some steps, step 1 "Remove the protective cap from mouthpiece of the DPI", step 2 "Prepare the DPI dose as instructed in the 
Table 2 The overall number of mistakes of each step in the three visits

\begin{tabular}{lllll}
\hline Step number and details & 1st visit & 2nd visit & 3rd visit & $\boldsymbol{p}$ value \\
\hline 1. Remove the protective cap from mouthpiece of the DPI & - & - & - & NS \\
2. Prepare the DPI dose as instructed in the patient pamphlet & - & - & - & NS \\
3. Breathe out as far as comfortable & 121 & 64 & 33 & $<0.001$ \\
4. Place the DPI mouthpiece between the teeth and seal with lips ${ }^{\#}$ & 126 & 76 & 65 & $<0.001$ \\
5. Ensure your tongue does not obstruct the mouthpiece & - & - & - & NS \\
6. Inhale as fast and deep as possible & 260 & 227 & 158 & $<0.001$ \\
7. Maintain a fast inhalation rate until the lungs are full & 260 & 225 & 158 & $<0.001$ \\
8. Remove the DPI from the mouth and hold breath for 5-10 s & 220 & 139 & 123 & $<0.001$ \\
9. If more than one dose each time, wait about 30 s before the next dose* & 52 & 66 & 18 & $<0.001$ \\
10. Rinse mouth, and if possible brush teeth after dosing & 142 & 80 & 53 & $<0.001$ \\
11. Replace cap on the DPI & 25 & 13 & 0 & NS \\
Total number of mistakes & 1206 & 890 & 608 & $<0.001$ \\
\hline
\end{tabular}

$N S$ no significant difference

${ }^{*}$ No significant difference between 1 st and 2 nd visits

\# No significant difference between 3 rd and 2nd visit

patient pamphlet", and step 5 "Ensure your tongue does not obstruct the mouthpiece", showed no mistakes in the three visits. These steps were spontaneously done during routine use of the DPI.

There was no significant difference between the three age groups in the mean number of mistakes. However, the change in mean number of mistakes between the 3rd and 1st visits was highest, but with no significant difference in GP2 (40-60 years old), who might be more keen to learn how to control their asthma compared to the other groups. Also, it was found that most of the older adult DPI users had more experience in using a DPI than the younger users. This was observed in the slightly higher mean number of mistakes at the 1st visit in GP1 (young group) followed by no significant difference in 2 nd and 3rd visits.
GP3 was the group with least improvement after the 3rd visit. That might be due to their theoretical believes that they were already doing the correct inhalation technique or due to learning capacity and memory factors [22]. The learning capacity problem was obvious in step 4, "Place the DPI mouthpiece between the teeth and seal with lips" In GP3 (very old patients); no significant difference was found between the 2 nd and the 3rd visits in the total number of mistakes for step 4. It was very difficult for GP3 (very old patients) to remember to place the DPI mouthpiece between the teeth not only between lips.

From the resulting number of mistakes, we can recommend the DPI as a very easy method of delivering medication for asthmatic patients with one condition, which is continuous counselling [36]. Also, the ability to use 
correctly an inhaler can be positively correlated with counselling, age, and experience.

However, two previous studies had shown that there was no effect of age or education [13, 25]. This different result can be attributed to the patients they studied, as they were all newly diagnosed patients who might have less DPI experience.

A higher inspiratory flow is required to operate a DPI, meaning that it may not be appropriate for patients with very severe asthma [38] or very old patients, e.g., GP3 [25]. They need to use a DPI with low resistance or inhale twice from their DPI [30]. However, this was not observed in the present study as the Aerolizer is a DPI with very low resistance that allows most asthmatic patients to receive the inhaled dose easily.

When looking at the pulmonary function test (PFT) results, it was found that there were improvements in the patients' $\mathrm{PEF}$ and $\mathrm{FEV}_{1} /$ FVC\%. However, the improvement in PFTs was slower than in the number of mistakes. The comparison between the 1st and 2 nd visits in the PEF and the $\mathrm{FEV}_{1} / \mathrm{FVC} \%$ showed no significant improvement, but the improvement was significant at the 3rd visit $(p<0.001)$. Similarly, asthmatics and COPD patients receiving education showed a significant increase $(p<0.001)$ in PEF, $\mathrm{FEV}_{1}$, and FVC values over a final month of follow-up $[15,17,39,40]$.

Repeated counselling showed a beneficial effect on pulmonary function tests in all age groups, especially in GP3 ( $>60$ years old). This group of patients may need continuous counselling and follow-up due to expected age-related memory problems with cognitive decline and poor vision. These factors might led to inhaler misuse [22].

The effects of Aerolizer counselling on PEF, $\mathrm{FEV}_{1} / \mathrm{FVC} \%$ were similar to our previously published effects of MDI counselling [4]. This was expected, as the improvement in pulmonary function tests with patient adherence to treatment and correct use of their inhaler, either DPI or MDI, should improve the patients' PFTs regardless the type of the device they use [1, 15-17].

However, the total number of mistakes when using an MDI was much higher than with a DPI for all groups in all visits. This could mean that even though the counselling has an improving effect on both DPI and MDI inhalation technique, the DPI was still much easier than the MDI. That may be due to coordination needed when using the MDI or cold freon effect that occurs with the MDI [25, 27].

These cumulative clinical improvement results supports the importance of the recent call for action published in the European Respiratory Society Journal [5], which emphasized the importance of correct inhaler choice, proper training, and ongoing education to maintain technique qualities.

\section{CONCLUSION}

Inhalation technique should be checked and reinforced at regular intervals, especially for very old patients who might have greater difficulty in perfectly using a DPI. Continuous counselling could result in improvement in the quality of life of the patients by improving their lung function. Critical errors in DPI inhalation technique, e.g., not inhaling fast and maintaining fast inhalation, must be avoided and taught well to the patient.

The limitation of the present study was the large number of DPIs with different methods of dose preparation and airflow resistance that makes it very hard to include in one study. 
Hence, we recommend more counselling studies using different types of DPI, with and without the introduction of training aid devices.

\section{ACKNOWLEDGMENTS}

No funding or sponsorship was received for this study or publication of this article. All named authors meet the International Committee of Medical Journal Editors (ICMJE) criteria for authorship for this manuscript, take responsibility for the integrity of the work as a whole, and have given final approval for the version to be published.

Compliance with ethics guidelines. All procedures followed were in accordance with the ethical standards of the responsible committee on human experimentation (institutional and national) and with the Helsinki Declaration of 1964, as revised in 2013. Informed consent was obtained from all patients for inclusion in the study.

Disclosures. M. O. Elgendy, M. E. Abdelrahim and R. S. Eldin declare no conflict of interest.

Open Access. This article is distributed under the terms of the Creative Commons Attribution-NonCommercial 4.0 International License (http://creativecommons.org/licenses/ by-nc/4.0/), which permits any noncommercial use, distribution, and reproduction in any medium, provided you give appropriate credit to the original author(s) and the source, provide a link to the Creative Commons license, and indicate if changes were made.

\section{REFERENCES}

1. Bousquet J, Mantzouranis E, Cruz AA, Aït-Khaled N, Baena-Cagnani CE, Bleecker ER, et al. Uniform definition of asthma severity, control, and exacerbations: document presented for the World Health Organization Consultation on Severe Asthma. J Allergy Clin Immunol. 2010;126(5):926-38.

2. Press VG, Arora VM, Shah LM, Lewis SL, Ivy K, Charbeneau J, et al. Misuse of respiratory inhalers in hospitalized patients with asthma or COPD. J Gen Intern Med. 2011;26(6):635-42.

3. Melani AS, Bonavia M, Cilenti V, Cinti C, Lodi M, Martucci $\mathrm{P}$, et al. Inhaler mishandling remains common in real life and is associated with reduced disease control. Respir Med. 2011;105(6):930-8.

4. Elgendy MO, Abdelrahim ME, Salah Eldin R. Potential benefit of repeated MDI inhalation technique counselling for patients with asthma. Eur J Hospital Pharm. 2015; doi:10.1136/ejhpharm2015-000648 (In press).

5. Papi A, Haughney J, Virchow J, Roche N, Palkonen $S$, Price D. Inhaler devices for asthma: a call for action in a neglected field. Eur Respir J. 2011;37(5):982-5.

6. Schramm B, Ehlken B, Smala A, Quednau K, Berger $\mathrm{K}$, Nowak D. Cost of illness of atopic asthma and seasonal allergic rhinitis in Germany: 1 year retrospective study. Eur Respir J. 2003;21(1):116-22.

7. Herjavecz I, Boszormenyi Nagy G, Gyurkovits K, Magyar P, Dobos K, Nagy L, et al. Cost, morbidity, and control of asthma in Hungary: the Hunair study. J Asthma. 2003;40(6):673-81.

8. Sullivan S. The burden of uncontrolled asthma on the US health care system. Manag Care. 2005;14(8):4-7 (discussion 25-7).

9. Godard P, Chanez P, Siraudin L, Nicoloyannis N, Duru G. Costs of asthma are correlated with severity: a 1-year prospective study. Eur Respir J. 2001;19(1):61-7.

10. Leigh JP, Yasmeen S, Miller TR. Medical costs of fourteen occupational illnesses in the United States in 1999. Scand J Work Environ Health. 2003:304-13.

11. Giraud V, Roche N. Misuse of corticosteroid metered-dose inhaler is associated with decreased asthma stability. Eur Respir J. 2002;19(2):246-51. 
12. Roche N, Chrystyn H, Lavorini F, Agusti A, Virchow JC, Dekhuijzen R, et al. Effectiveness of inhaler devices in adult asthma and COPD. Eur Med J. 2013;1:64-71.

13. Hämmerlein A, Müller U, Schulz M. Pharmacist-led intervention study to improve inhalation technique in asthma and COPD patients. J Eval Clin Pract. 2011;17(1):61-70.

14. Dantic DE. A critical review of the effectiveness of 'teach-back'technique in teaching COPD patients self-management using respiratory inhalers. Health Edu J. 2014;73(1):41-50.

15. Andreevska K, Petkova V, Jordanova S, Grekova D, Madjarov V, Dimitrova M, et al. Effect of education on patients with chronic obstructive pulmonary disease. World J Pharm Pharm Sci. 2013;3(3):01-9.

16. Shareef J, Sajitha M, Shastry C. Impact of pharmacist provided patient counseling on quality of life inpatients with asthma in a tertiary care teaching hospital. Int $\mathrm{J}$ Pharma Res Rev. 2014;3(2):1-10.

17. Saji M, Alhas JJK, Siraj S. Study on the impact of patient counseling on the quality of life and pulmonary function of asthmatic patient. Int $\mathrm{J}$ Pharm Pharm Sci. 2012;4(Suppl 5):300-4.

18. Tan N, Ng C, Goh S, Lee C. Assessment of metered dose inhaler technique in family health service patients in Singapore. Singapore Med J. 1999;40(7):465-7.

19. Molimard M, Le Gros V. Impact of patient-related factors on asthma control. J Asthma. 2008;45(2):109-13.

20. Basheti IA, Reddel HK, Armour CL, Bosnic-Anticevich SZ. Improved asthma outcomes with a simple inhaler technique intervention by community pharmacists. J Allergy Clin Immunol. 2007;119(6):1537-8.

21. Lareau SC, Yawn BP. Improving adherence with inhaler therapy in COPD. Int J Chronic Obstruct Pulmonary Dis. 2010;5:401-6.

22. To KW, Lee WM, Choi KC, Yu D, Chau J, Lee I. Educational and supportive interventions for improving adherence to inhalation therapy in people with chronic respiratory diseases: a systematic review protocol. JBI Database Syst Rev Implement Rep. 2013;11(1):329-45.

23. Bryant J, McDonald VM, Boyes A, Sanson-Fisher R, Paul C, Melville J. Improving medication adherence in chronic obstructive pulmonary disease: a systematic. Respir Res. 2013;14:109.
24. Lavorini F. The Challenge of Delivering Therapeutic Aerosols to Asthma Patients. ISRN Allergy. 2013;2013:1-17. doi:10.1155/2013/102418.

25. Lavorini F, Magnan A, Christophe Dubus J, Voshaar T, Corbetta L, Broeders M, et al. Effect of incorrect use of dry powder inhalers on management of patients with asthma and COPD. Respir Med. 2008;102(4):593-604.

26. Newman S. Inhaler treatment options in COPD. Eur Respir Rev. 2005;14(96):102-8.

27. Hilton S. An audit of inhaler technique among asthma patients of 34 general practitioners. Br J Gen Pract. 1990;40(341):505-6.

28. Kamps A, Brand P, Roorda R. Determinants of correct inhalation technique in children attending a hospital-based asthma clinic. Acta Paediatr. 2002;91(2):159-63.

29. Newman S, Busse W. Evolution of dry powder inhaler design, formulation, and performance. Respir Med. 2002;96(5):293-304.

30. Abdelrahim ME. Emitted Dose and Lung Deposition of Inhaled Terbutaline from Turbuhaler at Different Conditions. Respir Med. 2010;104(5):682-9.

31. Abdelrahim M, Assi K, Chrystyn H. Dose emission and aerodynamic characterization of the terbutaline sulphate dose emitted from a Turbuhaler at low inhalation flow. Pharm Dev Technol. 2013;18(4):944-9.

32. Azouz W, Chetcuti P, Hosker HS, Saralaya D, Stephenson J, Chrystyn $H$. The inhalation characteristics of patients when they use different dry powder inhalers. J Aerosol Med Pulm Drug Deliv. 2014;28(1):35-42.

33. Adachi YS, Adachi Y, Itazawa T, Yamamoto J, Murakami G, Miyawaki T. Ability of preschool children to use dry powder inhalers as evaluated by In-Check Meter. Pediatr Int. 2006;48(1):62-5.

34. Broeders ME, Molema J, Vermue NA, Folgering HTM. In check dial: accuracy for Diskus and Turbuhaler. Int J Pharm. 2003;252(1):275-80.

35. Chrystyn H. Is inhalation rate important for a dry powder inhaler? Using the in-check dial to identify these rates. Respir Med. 2003;97(2):181-7.

36. Rau JL. Practical problems with aerosol therapy in COPD. Respir care. 2006;51(2):158-72.

37. Sims MW. Aerosol therapy for obstructive lung diseases. Chest. 2011;140(3):781-8. doi:10.1378/ chest.10-2068. 
38. Tashkin DP, Ferguson GT. Combination bronchodilator therapy in the management of chronic obstructive pulmonary. Respir Res. 2013;14:49.

39. Shrestha R, Shakya R. Comparison of bronchodilator effect of salbutamol delivered via
MDI and DPI in COPD patients. SAARC J Tuberculosis Lung Dis HIV/AIDS. 2009;6(2):22-30.

40. Chipps BE. Inhaled corticosteroid therapy for patients with persistent asthma: learnings from studies of inhaled budesonide. Allergy Asthma Proc. 2009;30(3):217-28. 